\title{
ENFERMAGEM E AIDS: SABER E PARADIGMA
}

\author{
lara de Moraes Xavier* \\ Josete Luzia Leite** \\ Gláucia Maria Braga*** \\ Paulo Henrique Silva Nunes ****
}

\begin{abstract}
XAVIER, I.de M.; LEITE, J L.; BRAGA., G. M.; NUNES, P.H.S. Enfermagem e AIDS: saber e paradigma Rev.latino-am.enfermagem, Ribeirão Preto, v. 5, n. 1. p. 65-73, janeiro 1997.

Este trabalho consiste num recorte de uma pesquisa que aborda a reação entre o Saber em Enfermagem e a AIDS. Caracteriza a época atual como um período de transição entre o paradigma da ciência moderna e um novo paradigma, de cuja emergência se vão acumulando os sinais, denominada ciência pós-moderna. Traz a dinâmica da AIDS no Brasil a partir de 79.908 casos notificados de 1980 a 1996. O objetivo principal é descrever o saber de enfermagem que tem fundamentado a assistência de enfermagem prestada aos pacientes soropositivos e com AIDS em um Hospital Universitário situado no Rio de Janeiro.
\end{abstract}

UNITERMOS: saber em enfermagem, AIDS, paradigma

\section{INTRODUÇÃO}

\begin{abstract}
"A AIDS invadiu nossa sociedade, abalou nossas certezas, sacudiu nossos preconceitos e suscita a questão da solidariedade mundial. Três milhões de doentes no mundo, 17 milhões de soropositivos. A epidemia ganha terreno na África, no Sul e no Sudeste asiáticos. Diante deste novo flagelo, conseqüência negativa de uma civilização de intercâmbios em escala mundial, vão a medicina, a ciência permanecer impotentes?"
\end{abstract}

(Luc Montagnier, 1995)

O presente trabalho consiste num recorte de uma pesquisa institucional denominada $\mathbf{O}$ Saber em Enfermagem e AIDS - repensando o paradigma que aborda a relação entre o Saber de Enfermagem e a AIDS. Ele objetiva discutir esta temática tendo como referencial o estudo de ALMEIDA \& ROCHA (1986) que apresenta esse saber descrito em três momentos historicamente determinados:

- centralização na tecnológica;

- aplicação dos princípios científicos à enfermagem;

- teorias de enfermagem.

Nesse sentido, são tratados primeiramente alguns aspectos conceituais e históricos da AIDS, situando-a como um dos mais graves problemas para a saúde pública. Após esta fase, procura-se discutir sobre a AIDS no Brasil e as perspectivas dessa epidemia. Dentro deste cenário são analisados artigos publicados na Revista Brasileira de Enfermagem que abordam o tema Enfermagem e AIDS e os depoimentos de enfermeiras (os) que cuidam de pacientes com AIDS em um hospital universitário do Rio de Janeiro. As categorias principais de análise são as concepções de saber e de paradigma.

A partir da análise conclui-se que a assistência de enfermagem prestada a essas pessoas tem se caracterizado como uma assistência humanizada e qualificada, com ênfase nos aspectos biológicos e técnicos, sem uma visão antropológica e social. O paradigma que fundamenta essa assistência é, o hegemônico em saúde, isto é, o biomédico pautado na concepção cartesiana.

\footnotetext{
* Livre Docente e Mestre em Enfermagem, Professora Adjunta da Escola de Enfermagem Alfredo Pinto da Universidade do Rio de Janeiro. Doutoranda em Saúde Pública na ENSP/FIOCRUZ

** Doutora e Livre Docente em Enfermagem, Professora Titular da Escola de Enfermagem Alfredo Pinto da UNI-RIO. PróReitora de Pós-Graduação, Pesquisa e Extensão da UNI-RIO)

*** Aluna do Curso de Graduação em Pedagogia da Escola de Educação da UNI-RIO e bolsista. PIBIC/CNPq

**** Aluno do Curso de Graduação em Enfermagem da Escola de Enfermagem Alfredo Pinto da UNI-RIO e bolsista PIBIC/CNPq
} 


\section{AIDS - ASPECTOS CONCEITUAIS E HISTÓRICOS}

Esta doença transmissível, denominada AIDS, teve o seu primeiro reconhecimento oficial publicado no diário do Center for Disease Control do Serviço de Saúde dos Estados Unidos, em 1981. Dois anos depois, 1983, o agente responsável por ela foi isolado pela primeira vez. No ano seguinte, a demonstração do papel causal desse agente na AIDS foi aceita por toda a comunidade científica. Em 1985 surgiram os primeiros testes comerciais de detecção do vírus.

Ela ataca o sistema imunológico das pessoas e é causada pelo vírus da imunodeficiência humana (HIV). Doença crônica, sua evolução geralmente é lenta, podendo levar dez anos entre a contaminação e o momento em que a pessoa desenvolve a doença. Nesse intervalo, ela é "soropositiva".

A história natural da doença compreende várias etapas bem definidas: a primo-infecção, a fase silenciosa e a doença clínica. Num certo número de casos, a contaminação se traduz por uma infecção aguda, cujas manifestações são aparentemente banais e que dura de alguns dias a algumas semanas. A reação do organismo a essa primo-infecção é determinante para a evolução da infecção. Mecanismos de transmissão do HIV são os que dependem do sangue ou derivados e do relacionamento sexual, através do esperma e da secreção vaginal. Outro mecanismo refere-se à amamentação de recém nato Dor mulher infectada.

Ainda não existe tratamento definitivo da AIDS. Não obstante, progressos indubitáveis foram realizados desde o início dos anos 80. Eles permitiram prolongar a vida dos doentes. Por conta desta realidade, a ausência de cura, a prevenção assume uma posição de destaque nesse cenário.

A prevenção bem-sucedida se baseia em três elementos: informação e educação, serviços de saúde e assistência social adequados às necessidades da comunidade que sofre as conseqüências da epidemia e apoio social. Desta tripla perspectiva, vinculam-se as dimensões individual, social e institucional/estatal da vulnerabilidade à AIDS (MANN,1993).

A princípio, década de 80 , acreditava-se que a AIDS fosse uma doença que atacava apenas alguns grupos, chamados grupos de risco, agrupamentos constituídos por homossexuais, toxicômanos e hemofílicos. Hoje, esse discurso mudou, já que a doença se alastra para fora desses grupos específicos. O comportamento epidemiológico da doença, no Brasil, arrebentou com este "discurso científico" e mostrou a necessidade da busca urgente de um novo paradigma explicativo.

Desde o seu surgimento, a AIDS vem-se construindo como uma epidemia que ameaça fortemente não apenas a ordem social, mas até mesmo a espécie humana, por ser uma doença sexualmente transmissível que acomete majoritariamente adultos jovens em idade reprodutiva, e que tem levado, invariavelmente, esses doentes à morte.

Para PARKER (1994), durante grande parte da última década, a AIDS foi vista sobretudo como uma questão essencialmente biomédica, que confronta indivíduos isoladamente. Mas o argumento do autor, contrário a esta idéia, é de que: "o HIVIAIDS deve ser entendido, como todos os aspectos da saúde e da doença, como fundamentalmente coletivo - um constructo social que se molda dentro do contexto de sistemas sociais, culturais, políticos e econômicos altamente específicos, porém interligados e sobrepostos". (PARKER, 1994).

Após a leitura do livro "Para o amigo que não me salvou a vida", de GUIBERT (1995), reafirmou-se o quanto a AIDS é devastadora e enigmática. $O$ autor narra assim a sua experiência: “... a AIDS na verdade não é uma doença, só simplifica as coisas dizer que ela é isso, é um estado de fraqueza e de abandono que abre a jaula da fera que se carrega dentro de si, à qual sou obrigado a dar plenos poderes para que me devore, a quem deixo fazer com meu corpo vivo o que ela iria fazer com meu cadáver para desintegrá-lo. Os cogumelos da pneumocistose, que são para os pulmões e para a respiração como jibóias, e os da toxoplasmose, que arruínam o cérebro, estão presentes no interior de qualquer homem, simplesmente o equilíbrio de seu sistema imunológico os impede de ter direito de cidadania, ao passo que a AIDS Ihes dá o sinal verde, abre as comportas da destruição". (GUIBERT, 1995).

O inimigo - HIVIAIDS - é tão complexo, que, segundo XAVIER et al (1994), para combatê-lo, efetivamente, há que se adotar um conjunto de estratégias de enfrentamento não apenas mercadológicas e massificadas, mas sim uma postura que compreenda a AIDS como uma ameaça social que necessite de uma verdadeira revolução científica, de uma política de solidariedade, baseada no respeito à diferença cultural e na luta por justiça social.

A AIDS, certamente, tem a "cara" da cultura da sociedade onde se desenvolve. Inegavelmente, é uma epidemia mundial e em toda a parte é a mesma epidemia. Ainda mais inegável, em cada parte a AIDS tem uma especificidade ligada a determinações culturais que fazem com que em cada país/estado/cidade/bairro ela tenha a "cara" do meio onde cresce.

Segundo MOTA (1995), além de uma síndrome da imunodeficiência, conceito dado sob uma perspectiva biológica, AIDS é uma síndrome de representações que articula muito bem categorias subjetivas dos indivíduos na sociedade sob o prisma sociológico. 


\section{EPIDEMIOLOGIA DA AIDS}

NASCIMENTO (1996) baseado em números da Organização Mundial de Saúde (OMS) afirma que: "a AIDS atingiu no início de 96 a marca dos 17 milhões de infetados (doentes ou não) em todo o mundo". Este número revela salto na disseminação da epidemia, caracterizando-se como uma pandemia internacional. $O$ Brasil é o país latino-americano mais afetado pelo HIVIAIDS.

A epidemia de AIDS no Brasil teve início nas duas maiores regiões metropolitanas, São Paulo e Rio de Janeiro, ambas situadas na região Sudeste, que apresentam, hoje, taxas de incidência acumulada elevadas: São Paulo, 226.5/100.000 habs. e Rio de Janeiro 147.7/100.000 habs. (BRASIL. MS., 1996). A epidemia torna-se visível do ponto de vista médico e social nos primeiros anos da década de 80 , entre homossexuais masculinos, tendo sido os dois primeiros casos notificados na Cidade de São Paulo em 1982.

Foram registrados no Ministério da Saúde, de 1980 a 1996, 79.908 casos. (BRASIL. MS.,1996). A AIDS vem mostrando tendência crescente, a partir dos primeiros casos notificados, em todos os Estados da Federação. Esses casos se concentram especialmente nos estados de São Paulo e Rio de Janeiro, considerados portas de entrada da infecção no país, perfazendo $69 \%$ do total de notificações.

A situação do Brasil com relação à AIDS é muito preocupante, pois ele ocupa o terceiro lugar na lista de países com maior número de casos de AIDS, superado apenas pelos Estados Unidos e Uganda. O Ministério da Saúde informa que a transmissão do HIV ocorre, acima de tudo, através dos contatos sexuais.

Esta informação é confirmada pelos indicadores epidemiológicos que demonstram um deslocamento no perfil da síndrome - caracterizado inicialmente pelo homossexual e bissexual masculino, para incluir, cada vez mais, a mulher de 15 a 45 anos de idade e criança de zero a 5 anos de idade no rol de casos notificados. A proporção de casos entre homem e mulher tem se estreitado, de 1:28 casos em 1985, para 1:3 em 1996 (BRASIL. MS., 1996). Esta relação tende a indicar uma "feminização" do percurso do vírus no Brasil, bem como a sua "proletarização" ou "pauperização" ao analisar-se as alterações de parâmetros sócio-econômicos básicos entre casos notificados ao longo do período de evolução da doença. As análises apontam para uma incidência crescente no período de casos novos da doença em pessoas pertencentes aos estratos sócioeconômicos mais pobres.

PASSOS (1995) no artigo publicado no jornal O Globo de 16/9/95, cita a advertência que a Organização Mundial de Saúde faz ao comunicar o comportamento do vírus: "o vírus da AIDS contamina seis mil pessoas a cada dia, quatro por minuto. Atualmente, a África é o continente mais afetado com $70 \%$ dos casos. A OMS estima que há 4,5 milhões de doentes e 19 milhões de infectados em todo o mundo. Esse número deve dobrar até o ano 2000, sendo que os países do Terceiro Mundo concentrarão $90 \%$ dos casos". Nesses países a AIDS está se alastrando num ritmo assustador.

No Estado do Rio de Janeiro até dezembro de 1995, onze mil novecentos e noventa e cinco casos de AIDS foram notificados a Divisão de Controle de DST/AIDS da Secretaria de Estado de Saúde desse Estado. Destes 10949 (91,27\%) estão na Região Metropolitana do Estado onde se concentram os cinco municípios com maior número absoluto de casos (Rio de Janeiro, Niterói, Nova Iguaçu, Duque de Caxias e São Gonçalo).

Pode-se observar que cerca de $83 \%$ dos casos, tanto em homens quanto em mulheres, encontra-se nas faixas etárias compreendidas entre 20 e 49 anos, ou seja, uma população em idade reprodutiva, sexualmente e economicamente ativa. A transmissão sexual continua sendo responsável pelo maior número absoluto de casos (7259) seguida da transmissão por sangue (1654), e perinatal (110). No que se refere a distribuição dos casos segundo categoria de exposição e período de diagnóstico podese observar que nos homens e mulheres adultos a transmissão sexual em heterossexuais apresenta uma tendência ascendente. Já nos casos por transmissão sanguínea constata-se uma redução proporcional nos receptores de sangue. A razão homem/mulher vem diminuindo, passando de 9/1 em 1989 para 3/1 em 1995, coerente com o quadro nacional (PASSOS, 1995).

\section{SABER E PARADIGMA: CATEGORIAS DE ANÁLISE}

Segundo JAPIASSU (1986), o termo saber tem hoje, por força das coisas e pela realidade do uso, um sentido bem mais amplo que o termo CIÊNCIA. É considerado saber todo um conjunto de conhecimentos metodicamente adquiridos, mais ou menos, sistematicamente organizados e susceptíveis de serem transmitidos por um processo pedagógico de ensino. Neste sentido bastante lato, o conceito de saber poderá ser aplicado à aprendizagem de ordem prática (saber fazer, saber técnico, ...) e, ao mesmo tempo, às determinações de ordem propriamente intelectual e teórica. $E$ nesse último sentido que o termo saber foi utilizado neste trabalho.

Vale lembrar que antes do surgimento de um saber ou de uma disciplina científica, há sempre uma primeira aquisição ainda não científica de estados mentais 
já formados de modo mais ou menos natural ou espontâneo. No nível coletivo, esses estados mentais são constitutivos de uma certa cultura. Eles constituem as "opiniões primeiras" ou "pré-noções", tendo por função reconciliar o pensamento comum consigo mesmo, propondo certas explicações. Pode-se caracterizar tais pré-noções como um conjunto falsamente sistematizado de juízos, constituindo representações esquemáticas e sumárias, formadas pela prática e para a prática, obtendo sua evidência e sua autoridade das funções sociais que desempenham. Como dizia Aristóteles, "toda disciplina susceptível de se aprender, e todo estudo comportando um processo intelectual, constituem-se a partir de um conhecimento já presente". Todo saber humano relacionase a um pré-saber, conclui JAPIASSU (1986). O pré-saber é uma realidade cultural relativa ao saber ou à ciência: é relativamente ao saber que há um pré-saber.

$\mathrm{Na}$ perspectiva de análise aqui presente, considera-se que saber profissional é a forma histórica da relação entre classes e forças sociais e da relação entre Estado e Sociedade. A produção e a organização do saber profissional são processos de domínio e de legitimação de classe, de controle e de direcionamento da dinâmica social. O saber é uma forma de enfrentar desafios da natureza como de contornar ou estimular conflitos, de justificar ou criticar a ordem social, de articular a continuidade ou a transformação da sociedade e se coloca no processo da luta de classes e da correlação de forças sociais. O saber é práxis, concepção de mundo em conflito, relativo às relações de classes e forças sociais.

Com relação a categoria paradigma, destaca-se o estudo de Thomas Kuhn escrito em 1962 que introduziu a noção de paradigma no terreno da ciência (1992). Esse conceito disseminou-se e tem sido usado de forma muito ampla. Fala-se hoje em dia em mudanças de paradigma nas práticas humanas em geral, por força da existência de numerosos problemas no cenário do conhecimento humano que não conseguem mais ser resolvidos com base no velho modelo dominante, como por exemplo a epidemia de AIDS.

A época em que se vive deve ser considerada um período de transição entre o paradigma da ciência moderna e um novo paradigma, de cuja emergência se vão acumulando os sinais, e a que SANTOS (1987) chama ciência pós-moderna.

Dentre as diversas saídas possíveis para a crise epistemológica por que passa a ciência moderna, SANTOS (1987) destaca o esquema construtivista de KUHN (1992), elaborado em torno da categoria "paradigma".

KUHN (1992) apresenta o termo paradigma em sua obra A Estrutura das Revoluções Científicas: “(...) de um lado indica toda a constelação de crenças, valores, técnicas, etc., partilha das pelos membros de urna comunidade determinada. De outro, denota um tipo de elemento dessa constelação: as soluções concretas de quebra-cabeças que, empregadas como modelos ou exemplos, podem substituir regras explícitas como base para a solução dos restantes quebra-cabeças da ciência normal". (KUHN, 1992).

Para KUHN (1992), o progresso da ciência se faz pela quebra dos paradigmas, pela colocação em discussão das teorias e de seus métodos, acontecendo assim uma verdadeira revolução. Uma crise de paradigmas caracteriza-se como uma mudança de visão de mundo, conseqüência de uma insatisfação com os modelos anteriormente predominantes de explicação.

A crise de paradigmas leva geralmente a uma mudança de paradigmas, sendo que as mudanças mais radicais consistem em revoluções científicas.

O sentido mais empregado pelos diversos autores da expressão paradigma segundo KUHN (1992) é: "paradigmas são, no meu entender, realizações científicas universalmente reconhecidas que, durante algum tempo, fornecem modelos de problemas $e$ soluções para uma comunidade de profissionais".

\section{METODOLOGIA}

Estudo descritivo exploratório qualitativo apresenta a consolidação das análises de artigos que tratam da temática AIDS e Enfermagem publicados na Revista Brasileira de Enfermagem, e dos depoimentos fornecidos pelas (os) enfermeiras (os) que assistem pacientes com AIDS. O objetivo principal deste estudo é descrever o saber de enfermagem que fundamenta o assistir/cuidar implementado pela (0) enfermeira (0) junto a esses pacientes.

As técnicas de coleta de dados foram a análise documental e a entrevista semi-estruturada. Os instrumentos de trabalho de campo foram a planilha e o roteiro. Esta pesquisa foi concluída em julho de 1995.

Adotou-se a busca direta nos números da Revista Brasileira de Enfermagem (REBEn) editados no período de 1987 a 1992. Foram encontrados 197 artigos que tratam dos mais variados assuntos, destes somente três têm AIDS e Enfermagem como tema. Para efeito de contagem dos artigos, não foram incluídos os editoriais, os relatórios de comissões, os discursos e as conferencias.

Os artigos selecionados:

1) Procedimentos Técnicos Básicos na Prevenção da AIDS num Centro Cirúrgico de Grande Porte, publicado em 1988;

2) O Significado do Cuidado do Paciente com AIDS urna perspectiva de compreensão, publicado em 1991;

3) Perfil Epidemiológico da AIDS no Estado do Paraná e Região de Londrina - uma proposta para a assistência de enfermagem, publicado em 1991.

A REBEn, da Associação Brasileira de 
Enfermagem foi o periódico escolhido, por ser considerado o de maior circulação na Enfermagem Brasileira. De acordo com MENDES \& TREVISAN (1983), "a contribuição desta revista ao longo desses anos, à causa da enfermagem nacional, é de valor inestimável. Os profissionais responsáveis por esta revista sempre tiveram em mente a convicção de que ela precisa refletir o desenvolvimento profissional da enfermagem, portanto, sempre houve grande interesse em que as publicações fossem produzidas essencialmente por enfermeiros".

As (os) enfermeiras (os) que participaram da investigação, dando os seus depoimentos, trabalham em um hospital universitário situado no Rio de Janeiro.

Perfil dessas (es) cinco enfermeiras (os) que foram entrevistadas (os):

- sexo - 03 mulheres e 02 homens;

- idade - faixa etária entre 35 a 45 anos;

- formação - 3 com graduação em enfermagem e 02 com graduação em enfermagem e habilitação em enfermagem médico cirúrgica;

- tempo de serviço como Enfermeira (o) - 01 com 01 ano, 01 com 7 anos e 03 entre 11 a 14 anos;

- tempo que trabalha com AIDS - 01 há um mês, 01 há 7 anos, 02 há 10 anos e 01 há 11 anos.

\section{SABER DE ENFERMAGEM E A AIDS - (RE) VISITANDO O PARADIGMA}

O conjunto do material analisado, três artigos e cinco entrevistas evidenciou as seguintes visões de Enfermagem:

- enfermagem é uma ciência e uma atividade de amor e ética que cuida das pessoas;

- enfermagem é um trabalho que utiliza uma série de técnicas visando o bem estar das pessoas, mudando a situação encontrada.

Estas duas visões de enfermagem coincidem com as apresentadas por ALMEIDA \& ROCHA (1986) quando eles discutem o saber de enfermagem: "1) atividade de amor e solidariedade a serviço da humanidade - toma a enfermagem segundo critérios da ética moral do Cristianismo; 2) é aquela que considera a enfermagem como ciência - se preocupa em construir um campo de conhecimento próprio da enfermagem para dar-Ihe status de ciência, e 3) trabalho institucionalizado e que se relaciona e se articula com as outras práticas sociais, estabelecendo relação dialética com as sociedades especificas em que está inserido, uma relação de objeto de transformação e ao mesmo tempo de sujeito histórico de transformação".

Percebe-se no material analisado que as (os) enfermeiras (os) valorizam a padronização da assistência de enfermagem prestada aos pacientes com AIDS, como se seguissem um guia de condutas clínicas em AIDS com enfoque quase exclusivo no biológico e comportamental associado a princípios religiosos/assistenciais, não considerando os aspectos históricos, culturais e epidemiológicos da epidemia. Porém, se sobressai a importância da relação do indivíduo com o meio ambiente, este deve ser higiênico e saudável. Esta revelação demonstra o quanto a enfermagem de hoje, ainda se pauta pelo saber nightingaliano desenvolvido por Florence Nightingale, no século XIX, que tem uma base profundamente humanista e o seu sistema conceitual destaca o meio ambiente - Enfermagem Moderna.

Segundo ALMEIDA \& ROCHA (1986), o processo de evolução do saber de enfermagem foi marcado por etapas distintas: do enfoque eminentemente técnico para a busca dos princípios científicos; da utilização do método científico no planejamento da assistência de enfermagem para a formulação de teorias que dessem respaldo a esta assistência.

A despeito dessa assertiva verificou-se que na prática os profissionais investigados não utilizam uma metodologia para planejar a assistência de enfermagem nem mencionam teorias que fundamentem essa prática. Elas (es) enfatizam as técnicas, os procedimentos e os princípios científicos como elementos básicos dessa assistência. Esses elementos são considerados o próprio saber de enfermagem. Não valorizam a educação formal e sim a atualização através de publicações médicas.

A construção do saber em saúde na nossa sociedade vem, historicamente, caracterizando-se pela desarticulação entre o saber acadêmico e aquele que emerge do exercício da prática assistencial. Esta desarticulação guarda relação com o distanciamento existente entre o trabalho intelectual e o trabalho manual, característica do modo de produção capitalista que predomina na atual formação social brasileira. Regida pelos pressupostos do racionalismo positivista, a própria construção do saber universaliza os homens negando a sua diferenciação social e imobilizando a realidade, ignorando a sua dinamicidade e historicidade.

EGRY et al (1992) afirmam que na enfermagem brasileira, o saber acadêmico deriva de teorias que não contemplam a realidade social do país, acentuando com isso o distanciamento entre a academia e o serviço. Dessa maneira, continuam as autoras, o saber produzido na academia toma-se impossível de operacionalização, passando a existir concretamente apenas para um grupo social muito restrito, em geral constituído pelos enfermeiros ligados às instituições de ensino superior.

A análise das informações extraídas dos artigos e dos depoimentos evidenciou as seguintes características em relação ao saber de enfermagem que norteia a assistência prestada aos clientes HIVIAIDS: 
- preocupação em estabelecer normas, priorizam as atividades administrativas e burocráticas;

- padronização de técnicas, sistematização de procedimentos ou propostas de metodização, valorização da tecnologia sofisticada;

- ausência de análises explicativas;

- concepção naturalista da doença;

- ênfase nos treinamentos e orientação aos profissionais de enfermagem e clientes como forma de atualização;

- forte traço positivista;

- abordagem da temática AIDS com visão multiprofissional, porém com valorização para a assistência prestada pelos profissionais de enfermagem;

- as teorias de enfermagem não são mencionadas nem o processo de enfermagem, citam os princípios científicos e a relação homem-ambiente, porém não consideram a realidade social e histórica;

- descrição marcante da doença no que diz respeito a fisiopatologia, sintomatologia, diagnóstico laboratorial e terapêutica medicamentosa; pouca menção às atividades de prevenção;

- quando se referem ao corpo do paciente, este é visto! dividido em partes anatômicas. A especialização é considerada o ápice do conhecimento;

- valorização da prática, do cuidar, do fazer. Enfermagem vista como vocação e ideal, completamente descontextualizada e estática. Exercício da prática hospitalar com conotação técnica.

A concepção de enfermagem implícita nos discursos dos profissionais que participaram deste estudo é oposta a concepção que se firmou como o paradigma emergente da década de 80 , isto é, enfermagem enquanto prática social, formulado a partir dos trabalhos de CASTELLANOS (1988); ALMEIDA (1991); EGRY (1994), entre outros.

Com relação ao paradigma, fica claro no discurso das (os) enfermeiras (os), a dominância do modelo biomédico que está fundamentado na concepção cartesiana de ciência, que separa mente e corpo ou matéria, subdividindo-os em partes cada vez menores e tornando o conhecimento das partes cada vez mais pormenorizado, com excessiva valorização do método científico. A concepção de enfermagem é aquela que a coloca como uma vocação, arte e ideal, descontextualizada, universal e estática.

A crença cartesiana na verdade científica persiste ainda hoje no século $X X$, onde a tendência reducionista tem sido empregada na prática médica, de onde derivam também, a atuação de outros profissionais de saúde.

O modelo biomédico desenvolveu-se a partir de estudos da biologia, com base no pensamento de Descartes de que a ciência resolveria todas as questões da vida humana, constituindo-se em verdade absoluta e no único método válido para se chegar ao conhecimento real de determinado fenômeno.
Para Descartes (século XVII), a ciência possibilitava o controle e o domínio da natureza pelo homem através da tecnologia, alterando profundamente a natureza e o objeto da investigação científica da Antiguidade, os quais eram a sabedoria, a compreensão da ordem natural do universo e a vida em harmonia com ele. Com a concepção cartesiana e a divisão da natureza em matéria e mente, o universo material passou a ser visto como uma máquina regida por leis mecânicas conhecidas e determinadas. Já que a matéria era desprovida de vida ou espiritualidade podendo, portanto, ser explorada. Esta concepção mecanicista da matéria estendeu-se também aos seres vivos, que passaram a ser considerados e tratados como máquinas, tornandose possível explicar sua função, organização e a interrelação entre suas partes constituintes (KOLLER \& MACHADO, 1990).

A influência da concepção mecanicista da natureza se faz presente na atualidade, não só na prática médica, mas ainda constitui-se no paradigma dominante da ciência no mundo contemporâneo.

Com a fragmentação do corpo em partes cada vez menores, com o advento da especialização e o desenvolvimento de tecnologias altamente sofisticadas para tratá-las, o profissional de saúde, especialmente o de enfermagem, deixou de ver o ser humano como um todo contextualizado social e historicamente. Esses profissionais concentram-se exclusivamente no aspecto biológico da doença e no tratamento da parte afetada, elegendo o saber médico como o legítimo.

\section{CONSIDERAÇÕES FINAIS}

A AIDS é uma doença que veio neste final de século causar pânico em todo mundo e, ao mesmo tempo, colocar problemas a serem investigados e demonstrar a falência de muitas estruturas que se considerava como sagradas. Ela não é apenas um problema de saúde, mas, sim, um objeto de estudo complexo que envolve aspectos biológicos, sociais, psicológicos e, especialmente, éticos e legais. A AIDS atravessa contextos sócio-culturais os mais diversos e sua transmissão se dão através de interações íntimas entre pessoas. Portanto, a resposta a esta doença tem que ser produto de um trabalho interdisciplinar $e$ multiprofissional, isto é, abrangendo várias áreas de conhecimento. Para GLUCKSMANN (1994), esta resposta, além dos enfoques científicos e técnicos, deve contemplar as "implicações éticas e filosóficas da doença, as políticas públicas e atitudes existenciais de cada um diante da AIDS".

Segundo LEOPARDI (1994) é necessário penetrarmos em um outro campo, não o de um exclusivo marco científico, e, sim, num campo mais subjetivo, embora não menos importante que é o da filosofia. 
Para esta autora a filosofia permite tematizar, em profundidade, teorias e ações e enfrentar questões primárias do encadeamento da prática assistencial à saúde com o movimento da vida, para deixar para trás a inconsciência posta em nossa própria condição de sujeitos trabalhadores que atuam como prisioneiros de prescrições burocráticas ou morais, no redemoinho desta que chamamos sociedade contemporânea, ou sociedade da crise.

Fica evidente que a questão da ciência na enfermagem não é pura formalidade epistemológica. LEOPARDI (1994) defende que ela deve ser um compromisso profissional. Deve-se criar, formular e divulgar novos saberes, reconhecendo a articulação íntima existente entre o saber instrumental e o saber filosófico. Esta atuação profissional é categorizada também como uma ação política.

Dito de outra forma há necessidade de se associar a teoria à prática, para transformar a atividade em práxis, que vai validar o conhecimento.

De acordo com esta autora, existem três níveis conceituais da práxis da enfermagem:

(1) - construção de teorias sobre o cuidado;

(2) - definição de tecnologias;

(3) - prática do cuidado.

O saber deve ser entendido como um trabalho. Por ser um trabalho é uma negação reflexionante, isto é, uma negação que, por sua própria força interna, transforma algo que lhe é externo, resistente e opaco.

"O saber é o trabalho para elevar à dimensão do conceito uma situação de não-saber, isto é, a experiência imediata cuja obscuridade pede o trabalho da clarificação. A obscuridade de urna experiência nada mais é senão seu caráter necessariamente indeterminado $e$ o saber nada mais é senão o trabalho para determinar essa indeterminação, isto é, para torná-la inteligível. Só há saber quando a reflexão aceita o risco da indeterminação que afaz nascer, quando aceita o risco de não contar com garantias prévias e exteriores à própria experiência e à própria reflexão que a trabalha" (CHAUI, 1993).

Finalizando, reforça-se a necessidade de adoção do conceito foucaultiano de saber na área da saúde e, principalmente na enfermagem. Sabe-se desde FOULCAULT (1975), que os saberes acadêmicos nesta área não são neutros, puros, mas sim produzidos por instituições que têm objetivos de identificar, controlar e educar de acordo com outros objetivos dos poderes dominantes na sociedade.

Assim, coloca-se também a necessidade de um paradigma que dê conta de focalizar todos os aspectos inerentes à epidemia de AIDS e que garanta uma perspectiva mais dinâmica e uma visão não compartimentalizada do conhecimento, pautado nos princípios fundamentais da política de direitos humanos em HIVIAIDS mencionados por RODRIGUES (1996): "não-discriminação, dignidade, liberdade, privacidade, participação, responsabilidade e ética".

SANTOS (1987) fala do paradigma emergente que se fundamenta em um conhecimento prudente para uma vida decente. Esta argumentação teórica é muito adequada à realidade atual, que se encontra impregnada pelas doenças sexualmente transmissíveis. A AIDS tem alterado comportamentos e valores, normatizado condutas e relações sociais. Ela está presente no cotidiano das pessoas, principalmente através da mídia. A enfermagem deve considerar a AIDS mais do que uma síndrome da imunodeficiência, ela precisa ser abordada como uma síndrome de representações dentro de um contexto histórico social.

A reconstrução do saber de enfermagem e o repensar do paradigma dominante são tarefas primordiais que se colocam para os profissionais de enfermagem para que de fato se possa dar visibilidade a enfermagem como uma ciência social que constrói um campo de conhecimento, da área da saúde, dirigido ao ser humano, à comunidade e ao meio ambiente, que formula teorias e práticas historicamente determinadas sobre o cuidar no processo saúde-doença da coletividade, através de processos de trabalho.

Para ALMEIDA \& ROCHA (1986), os saberes e as práticas da enfermagem não são o produto somente do cientificismo técnico e o produto da enfermagem tomada isoladamente. O seu saber é histórico e, assim sendo, contempla a estrutura organizacional e política dos serviços de saúde e a estrutura social do país, na dinâmica das relações econômicas, políticas e ideológicas.

A partir destas considerações, propõe-se um novo olhar da (o) enfermeira (o) para esse problema grave e urgente AIDS, doença epidêmica desencadeada não somente pelo vírus da imunodeficiência humana, mas também pelos preconceitos, discriminações e injustiça social. Este olhar profissional deve perceber o mundo como uma totalidade complexa, e caracterizar o conhecimento também como realidade complexa. Como totalidades, mundo, conhecimento, saber e paradigma podem relacionar-se interdisciplinarmente. Porém, é fundamental gritar bem alto que o combate eficiente à difusão da AIDS começa com a preocupação com a vida e com os ideais de justiça. Como declaram PARKER \& DANIEL (1991):

"DEPENDE, ACIMA DE TUDO, DA NOSSA CAPACIDADE DE CONSTRUIR UMA POLÍTICA DA SOLIDARIEDADE DENTRO DE UMA SOCIEDADE DEMOCRÁTICA". 


\section{NURSING AND AIDS: KNOWLEDGE AND PARADIGM}

This study is a part of a research that comments the relation between Nursing Knowledge and AIDS. The actual period of time is treated like a period of transition between the modern science and one new paradigm. This is called post-modern science. It brings the dynamics of AIDS in Brazil after the registration of 79.908 cases from 1980 to 1996 . The main objective is to describe nursing knowledge that has based nursing care to soropositive and aidetic patients in a University-Hospital located in Rio de Janeiro, Brazil.

KEY WORDS: nursing knowledge, AIDS, paradigm

\section{ENFERMERÍA Y SIDA: SABER Y PARADIGMA}

Este trabajo, consiste en un recorte de una investigación que aborda la relación entre el Saber en Enfermería y el SIDA. Caracteriza la época actual, como un período de transición entre el paradigma de la ciencia moderna y un nuevo paradigma, de cuya emergencia se van acumulando las señales de la denominada ciencia post-moderna. Trae la dinámica del SIDA en el Brasil, a partir de 79.908 casos notificados de 1980 a 1996. El objetivo principal, es describir el saber que ha fundamentado la asistencia de enfermería prestada a los pacientes soropositivos y con SIDA, en un Hospital Universitario, situado en Rio de Janeiro, Brasil.

TÉRMINOS CLAVES: saber y enfermería, SIDA, paradigma

\section{REFERÊNCIAS BIBLIOGRÁFICAS}

01. ALMEIDA, M.C.P. O Trabalho de enfermagem e sua articulação com o processo de trabalho em saúde: rede básica de saúde de Ribeirão Preto. Ribeirão Preto, 1991. 279p. Tese (Livre Docência) - Escola de Enfermagem de Ribeirão Preto, Universidade de São Paulo.

02. ALMEIDA, M.C.P.; ROCHA, J.S.Y. O saber de enfermagem e sua dimensão prática. São Paulo: Cortez, 1986.

03. BRASIL. Ministério da Saúde. Programa Nacional de DST/AIDS. Boletim Epidemiológico, $\mathrm{n}^{\circ} 01$; Semana Epidemiológica 49 a 05, Brasília, dezembro - 95 a fevereiro - 96, 1996.

04. CASTELLANOS, B.E.P. O trabalho do enfermeiro - a procura e o encontro de um caminho para o seu estudo. Da abordagem mecânicofuncionalista à pesquisa emancipatória. São Paulo, 1987. 395 p. Tese (Doutorado) - Escola de Enfermagem, Universidade de São Paulo.

05. CHAUI, M. Cultura e democracia: o discurso competente e outras falas. 6. ed. São Paulo: Cortez, 1993.

06. EGRY, E.Y. et al. Processo de integração docente assistencial: espaço e movimento possíveis na construção do saber em saúde coletiva. Rev.Bras.Enfermagem, Brasília, v. 45, n. 1, p. 09-14, 1992.
07. EGRY, E. Elementos teórico-metodológicos para a intervenção práxica da enfermagem em saúde coletiva. São Paulo, 1994. 205p. Tese (Livre Docência) - Escola de Enfermagem, Universidade de São Paulo.

08. FOUCAULT, M. Surveiller et punir, naissance de la prison. Paris. Gallimard, 1975.

09. GLUCKSMANN, A. Glucksmann, os franceses e a AIDS. Caderno Idéias. Jornal do Brasil, $\mathrm{n}^{\circ}$ 395, 1994.

10. GUIBERT, H. Para o amigo que não me salvou a vida. Rio de Janeiro: José Olympio, 1995.

11. JAPIASSU, $H$. Introdução ao pensamento epistemológico. 4. ed. Rio de Janeiro: Francisco Alves, 1986.

12. KOLLER, E.M.P.; MACHADO, H.B. Reflexões sobre a prática da enfermagem e prenúncios de mudanças para 0 século $X X I$ Rev.Bras.Enfermagem, Brasília, v. 45, n. 1, p. 74-79, 1992.

13. KUHN, T.S. A estrutura das revoluções científicas. São Paulo: Perspectiva, 1992.

14. LEOPARDI, M.T. Entre a moral e a técnica: ambigüidades dos cuidados de enfermagem. Florianópolis: Editora da UFSC, 1994.

15. MANN, J. et al. A AIDS no mundo. Rio de Janeiro: ABIA/IMS-UERJ/Relume-Dumará, 1993. 
16. MENDES, I.A.C.; TREVISAN, M.A. As partes do conhecimento e as tendências subjacentes nos artigos publicados na Revista Brasileira de Enfermagem, de 1970 a 1981. Rev.Bras.Enfermagem, RS, v. 36, n. 2, p. 4550, 1983.

17. MOTA, M. P. Análise de metodologia de investigação: homossexualidade. In: CZERESNIA, D. et al., (org). AIDS - pesquisa social e educação. São Paulo: HUCITEC/Rio de Janeiro: ABRASCO, 1995.

18. NASCIMENTO, A. Apresentação. In: Dados. AIDS Uma Epidemia em Mutação. Rio de Janeiro: RADIS/FIOCRUZ, nº 18, 1996.

19. PARKER, R. A construção da solidariedade AIDS, sexualidade e política no Brasil. Rio de Janeiro: Relume-Dumará; UERJ - ABIA, 1994.
20. PARKER, R.; DANIEL, H. AIDS, a terceira epidemia: ensaios e tentativas. São Paulo; Iglu, 1991.

21. PASSOS, J. M. HIV infecta 6.000 por dia. Ciência e Vida. O GLOBO. setembro, 1995. RIO DE JANEIRO. Secretaria de Estado de Saúde do Rio de Janeiro; Superintendência de Saúde Coletiva, out/nov/dez de 1995.

22. RODRIGUES, L.G.M. Rede Nacional de Direitos Humanos em HIVIAIDS. Brasília: Ministério da Saúde, 1996.

23. SANTOS, B. de S. Um discurso sobre as Ciências. Porto: Afrontamento, 1987.

24. XAVIER, I.M. et al. AIDS: paradigma emergente. Rev.Enfermagem UERJ., Rio de Janeiro, v. 2, n² 2, p. 198-205, 1994. 